\title{
Effects of the motivation focus on manual grasping
}

\author{
Fabian Steinberg and Otmar Bock \\ German Sport University Cologne, Cologne, North Rhine-Westphalia, Germany
}

\begin{abstract}
We have shown before that grasping movements from a given starting position to a given object differ substantially when performed as a typical laboratory task (L) and when they are embedded in an everyday-like context (E). The present study investigates whether this context-dependence is related to the subjects' motivation focus. We manipulated subjects' motivation focus and observed significant effects of Context on performance, as in previous work, but also significant effects of Motivation and Context $\mathrm{x}$ Motivation on performance. The interaction term could not be interpreted as generally higher or lower motivation sensitivity in L than in E, and therefore it doesn't support the hypothesis that context-dependence of grasping can be reduced to motivation-dependence. We conclude that some brain areas contribute differently to $\mathrm{L}$ and to E, thus producing contextdependence, and that those areas are differently sensitive to motivation. Keywords: sensorimotor integration, motor control, prehension, human behavior, context.
\end{abstract}

Received 13 August 2013; received in revised form 16 October 2013; accepted 16 October 2013. Available online 23 December 2013.

\section{Introduction}

Grasping movements depend critically not only on the position, size and shape of the to-be-grasped object, but also on its intended use; this has been shown both with behavioral (Henry \& Rogers, 1960; Rosenbaum, Chapman, Weigelt, Weiss, \& van der Wel, 2012) and with neural-activation data (Grafton, 2010). We have recently documented that even if the position, size, shape and intended use of the object don't change, grasping movements are still not uniform: rather, they depend on the behavioral context in which they are embedded. Specifically, when subjects moved their hand from the same starting position to the same object in the same location, grasped it with the same (pinch) grip and moved it back and forth along the same path, their hand trajectories and forces differed substantially when this task was part of complex and meaningful behavior, versus when it was executed as an isolated motor act with no purpose beyond itself (Bock \& Hagemann, 2010). We argued that the latter context is typical for laboratory research (hence abbreviated ' $L$ '), while the former is more common in everyday life (hence abbreviated 'E').

Indeed, factor analyses revealed that the difference between $\mathrm{L}$ and $\mathrm{E}$ can't be traced back to a single cause but rather reflects several distinct processes (Bock

Fabian Steinberg and Otmar Bock, Institute of Physiology and Anatomy, German Sport University Cologne, Cologne, North Rhine-Westphalia, Germany. Correspondence regarding this article should be directed to: Fabian Steinberg, German Sport University Cologne, Institute of Physiology and Anatomy, Am Sportpark Müngersdorf 6, 50933 Cologne, Germany. Phone: (49) (221) 4982-6780. Email: fabian.steinberg@uni-mainz.de
\& Züll, 2013), and that it is modulated by a person's cognitive ability (Steinberg \& Bock, 2013b), age (Bock \& Steinberg, 2012) and exposure to weightlessness (Steinberg \& Bock, 2013a). Therefore we concluded that grasping movements are controlled by multiple, context-dependent functional modules that are differently sensitive to factors such as cognition, aging and gravitoinertial environment.

Our conclusion fits well with current views about the neural control of movement (Goodale, 2011; Grafton, 2010). It is assumed that motor activities such as grasping are processed by a dorsal, occipito-parietal pathway responsible for the visual guidance of actions, and by a ventral, occipito-temporal pathway that primarily serves visual perception (Milner \& Goodale, 1995). Direct and indirect neuronal connections (Knierim \& Van Essen, 1992; Morel \& Bullier, 1990) enable both streams to communicate with each other (Goodale, 2011) and with motor brain areas (Glickstein, 2000), so that visuomotor processing could well be flexibly redistributed between functional modules in the dorsal and ventral stream depending on context, cognitive abilities and other extraneous factors.

Although the context-dependence of grasping has been established by several studies, it still remains open exactly which differences between $\mathrm{L}$ and $\mathrm{E}$ are responsible for these findings. We have hypothesized earlier that differences regarding movement speed, repetitiveness and/or attention focusing might be critical, but experimental manipulations of those differences failed to modify context-dependence in a consistent fashion (Steinberg \& Bock, 2013c). The present study therefore evaluates yet another hypothesis: In L, subjects are explicitly instructed how to use their fingers 
for grasping, are told to grasp quickly and accurately, and are informed that their responses will be registered; this probably enhances their motivation to grasp as best as possible. In $\mathrm{E}$ however, instructions focus on the complex activity in which grasping is embedded and no information is given on how to grasp; subjects' may therefore not be highly motivated to grasp optimally. If so, L should be more sensitive to manipulations of motivation than $\mathrm{E}$, a prediction tested in the present study.

We decided to manipulate motivation in accordance with regulatory focus theory (Higgins, 1997, 1998), which posits that human actions are driven either by a promotion focus (i.e., desire to maximize gain and pleasure), or by a prevention focus (i.e., desire to minimize pain and loss). We therefore asked subjects to grasp either to gain a monetary reward or to prevent a monetary loss. To enhance either motivation focus, an established priming technique was administered before the actual experiment.

\section{Methods}

\section{Subjects}

48 right-handed subjects ( 24 male and 24 female, aged $23.27 \pm 3.61$ years) participated in this study. All reported to be free of musculoskeletal impairments and other diseases of the nervous system, and had not participated in other physiological studies within the last twelve months. All signed an informing consent statement. The study fulfills the declaration of Helsinki and has been approved by the institutional review board of the German Sport University.

\section{Experimental setup}

The setup was identical to our previous work. As illustrated schematically in Fig. 1, subjects sat at a table $70 \mathrm{~cm}$ away from a 17 " computer screen. A cylindrical lever of $4 \mathrm{~cm}$ length and $1.5 \mathrm{~cm}$ diameter was located $10 \mathrm{~cm}$ to the right of the screen, $16 \mathrm{~cm}$ above the table and $35 \mathrm{~cm}$ from its front edge; it was covered by a hood from three sides to ensure that it could only be grasped by thumb and index fingertip. The lever could be moved $3.5 \mathrm{~cm}$ towards the subject, until it met a mechanical stop. A displacement sensor (Burster ${ }^{\circledR} 8740$ ) registered the lever's position and a $6 \mathrm{df}$ force transducer (ATI ${ }^{\circledR}$ Nano 17) registered the forces applied to the lever, with sampling rates of $250 \mathrm{~Hz}$ per channel.

A joystick was placed on the table $16 \mathrm{~cm}$ in front of the subjects' body midline, its tip $12 \mathrm{~cm}$ above the table. The linear distance between joystick and lever was 32 $\mathrm{cm}$ horizontally and $4 \mathrm{~cm}$ vertically.

Six reflecting markers of $6 \mathrm{~mm}$ diameter were attached to the metacarpal bones of index finger and thumb of the right hand. The three-dimensional positions of these markers were registered by two Vicon ${ }^{\circledR}$ MX-F20 infrared cameras (sampling rate: $240 \mathrm{~Hz}, 1680 \times 1280$ pixels). A further, non-functional marker was attached to the subjects' middle finger, to ensure that subjects grasp exclusively with their index finger and thumb.

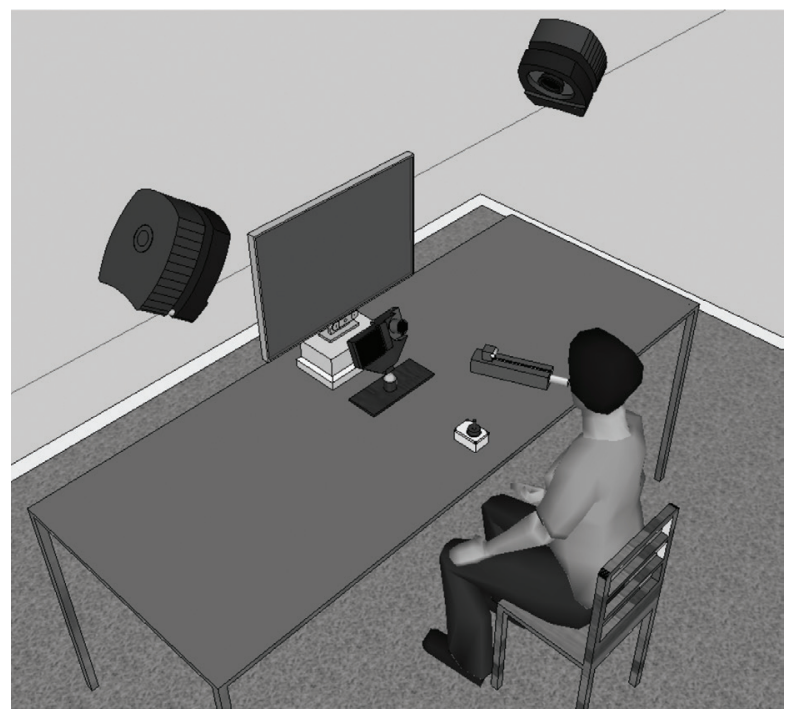

Figure 1: Scheme of the experimental setup, as explained in the text.

\section{Grasping tasks}

As in our previous work, subjects executed grasping movements either in a typical laboratory context (L) or in a context that more closely resembled many everyday situations (E). In L, the joystick's rod was mechanically fixed in its central position and subjects were asked to hold its tip between index finger and thumb. When a cartoon spider within a circle of $3 \mathrm{~cm}$ diameter was displayed on the screen along with a beep, subjects had to move their right hand towards the lever, grasp it with their index finger and thumb, pull it towards the mechanical stop, push it back to its starting position, and then return the hand to the joystick. They were instructed to move quickly without sacrificing accuracy. The spider was presented 20 times at intervals of 2 to 6 s, i.e., each subject executed 20 grasping responses. Depending on random protocol and grasping speed (random intervals began as soon as the lever reached its starting position) this task lasted between 140 and 180 s. Subjects performed three grasping movements in a practice trial before starting the task. The mean reward subjects earned in E was $3.97 \pm 0.36 €$.

In E, subjects were asked to play a spider-catching game. Cartoon spiders travelled across the screen from left to right at varying velocities, and subjects had to "hit" them with a joystick-driven cursor; each hit earned them a reward of 2 cents, which was displayed as a coin at the screen's right edge. After 10 seconds the game paused, and a stationary spider appeared in the center of the screen. To continue, subjects had to grasp with the right hand and move the lever in order to collect their reward and to start the next game level. Spider speed, and thus task difficulty, increased every fifth level. The game terminated after 20 levels, i.e., subjects executed 20 joystick-to-lever movements followed by lever displacement and hand returning to the joystick, just 
as in L. This task lasted between 240 and $260 \mathrm{~s}$, again depending on the grasping speed as described for L. Subjects performed three test levels that included three grasping movements as a practice trial before starting the task.

Summing up the two contexts differed with respect to repetitiveness, ecological validity, presence of instructions and availability of an extrinsic trigger signal. They didn't differ with respect to start and final object of the grasp, their location and required object handling.

\section{Manipulation of regulatory focus}

Established procedures (Brockner, Higgins, \& Low, 2004; Friedman \& Förster, 2005; Memmert, Unkelbach, \& Ganns, 2010) were used to prime subjects' motivation before they participated in the grasping task. Similar procedures have been used in the past, for example, to reveal the influence of the regulatory focus (Higgins 1997, 1998) on cognitive functions (e.g. Friedman \& Förster, 2005), sport performance (Memmert et al., 2010) and creativity (Friedman \& Förster, 2001). Here we used the Friedmann \& Förster (2001) approach: we produced a sheet of paper showing a mouse in the centre of a maze, and asked each subject to draw a line that guides the mouse to the exit. To enact a promotion focus (i.e. to activate the semantic concept of "seeking nurturance"), subjects were instructed to guide the mouse to a piece of cheese drawn outside the exit; to enact a prevention focus (i.e. to activate the semantic concept of "seeking security"), they were told to guide the mouse to a mouse hole drawn outside the exit and thus to save it from a bird of prey drawn looming above the labyrinth. Each subject completed either three mazes with a cheese, or three with a mouse hole.

The primed motivation focus was enhanced during the grasping task. Subjects primed for promotion were given the standard version of $\mathrm{E}$, which enacts promotion by the prospect of a monetary reward, or they were given a modified version of $\mathrm{L}$, which enacts promotion by announcing a drawing for a 30 Euro store voucher among the "best"- performing $20 \%$ of participants. Subjects primed for prevention were given a modified version of $\mathrm{E}$, in which 2 cents are subtracted from a 5 Euro stake for each spider not caught, or a modified version of $\mathrm{L}$, in which the 30 Euro draw was announced for all participants except the "worst"-performing 20\%. No definition of "best" and "worst" was provided, but after the study, we used the ratio of peak hand velocity and peak grip aperture as a criterion to enter subjects into the drawing. Thus, subjects in $\mathrm{L}$ either strived to be among the best, or not to be among the worst. This, of course, implies that the type of feedback subjects received during task execution were different in $\mathrm{L}$ and in E. However no other possibility was given without dramatically changing condition L.

Grasping context (L versus E) and regulatory focus (promotion versus prevention) were balanced across subjects, i.e., twelve subjects (6 male and 6 female) were manipulated with a promotion focus in $\mathrm{L}$ and twelve (6 male and 6 female) in E, twelve were manipulated with a prevention focus in L ( 8 male and 4 female) and the remaining twelve in $\mathrm{E}$ ( 4 male and 8 female).

\section{Questionnaire}

Prior to the main experiment and the manipulation of regulatory focus, subjects completed the German version of a questionnaire on subjects' habitual regulatory focus (Keller \& Bless, 2006; Lockwood, Jordan, \& Kunda, 2002; Plessner, Unkelbach, Memmert, Baltes, \& Kolb, 2009). This questionnaire consisted of 9 promotion and 8 prevention questions which had to be answered on a 7-point Likert scale.

\section{Data analysis}

Questionnaire responses were transformed into an index of regulatory strength (IRS) by subtracting the sum of response scores for prevention-related items from the sum for promotion-related items, such that positive IRS scores stand for a promotion focus (Keller $\&$ Bless, 2006). IRS of subjects with promotion and with prevention manipulation were compared with a t-test for independent means. As in our previous studies, grasping movements were analyzed with an interactive computer routine that reduced the kinematic and force data to 25 variables, as defined in Table 1. We then calculated the mean and the coefficient of variation $(\mathrm{CV})$ of each variable across all trials of a given subject, except trials with poor data quality $(<5 \%$, data was removed if one or more markers were not recorded by the cameras). This led to 49 parameters: 24 means, $24 \mathrm{CVs}$ and the parameter "peaks", which can't be split into a mean and a CV. Each parameter was then submitted to a separate $2 \times 2$ analysis of variance (ANOVA), with the betweenfactors Context (L, E) and Priming (promotion, prevention).

We then calculated the context difference for each parameter and subject

$\mathrm{p}^{\prime}=\mathrm{p}(\mathrm{L})-\mathbf{P}(\mathrm{E}) \quad$ or $\quad \mathrm{p}^{\prime}=\mathbf{P}(\mathrm{L})-\mathrm{p}(\mathrm{E}) \quad(1)$ where $p(L)$ and $p(E)$ are the scores of parameter $\mathrm{p}$ for an individual participating in $\mathrm{L}$ and $\mathrm{E}$, respectively, while $\mathbf{P}(\mathrm{L})$ and $\mathbf{P}(\mathrm{E})$ are the means of parameter $\mathrm{p}$ across all subjects participating in $\mathrm{L}$ and $\mathrm{E}$, respectively. Thus in effect, positive values of $\mathrm{p}$ ' indicate that $\mathrm{p}$ was higher in L than in E. p' scores were entered into three separate factor analyses, one for parameters with significant effects of Context in the above ANOVAs, one for those with significant effects of Priming and one for those with significant effects of Context x Priming. All factor analyses used Varimax rotation which preserves orthogonality. The number of extracted factors was determined according to parallel analysis (Horn, 1965), which is assumed to be more accurate than other methods (Fabrigar, Wegener, MacCallum, \& Strahan, 1999). Each factor analysis yielded a score for each subject and extracted factor, and we compared the scores of subjects in 
Table 1: description and acronyms of analyzed grasping parameters*

\begin{tabular}{|c|c|c|}
\hline & onym & description \\
\hline \multirow{7}{*}{ 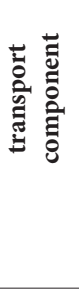 } & $\mathrm{TT}(\mathrm{s})$ & interval from movement onset to lever contact (transport time) \\
\hline & $\operatorname{Vmax}(\mathrm{cm} / \mathrm{s})$ & peak tangential hand velocity \\
\hline & skew-T & ratio of deceleration time (Vmax to lever contact) and TT \\
\hline & detour-V $(\mathrm{cm})$ & maximal vertical detour between actual and shortest possible hand path \\
\hline & detour- $\mathrm{H}(\mathrm{cm})$ & horizontal component of detour \\
\hline & GT $(s)$ & interval from finger opening onset to finger closing (grasping time) \\
\hline & PGA $(\mathrm{cm})$ & peak 3D distance from thumb to index finger (peak grip aperture) \\
\hline \multirow{2}{*}{ 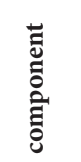 } & Peaks & (number of trials with multi-peaked aperture profiles) /(number of all trials) \\
\hline & $\mathrm{t}(\mathrm{PGA})(\mathrm{s})$ & interval from movement onset to PGA \\
\hline \multirow{6}{*}{ 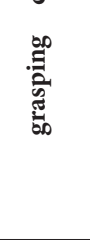 } & $\mathrm{t}(\mathrm{FGA})(\mathrm{s})$ & interval from PGA to lever contact (final grip aperture) \\
\hline & skew-G & ratio of $\mathrm{t}(\mathrm{FGA})$ and $\mathrm{GT}$ \\
\hline & incli-start $\left({ }^{\circ}\right)$ & hand inclination with respect to the horizontal at movement onset \\
\hline & incli-100 $\left(^{\circ}\right)$ & hand inclination $100 \mathrm{~ms}$ after onset \\
\hline & incli-PGA $\left({ }^{\circ}\right)$ & hand inclination at time of PGA \\
\hline & incli-end $\left(^{\circ}\right)$ & hand inclination at lever contact \\
\hline \multirow{2}{*}{ 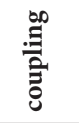 } & sync-start (s) & interval between onsets of finger opening and of hand transport \\
\hline & sync-peak (s) & interval between $\mathrm{t}(\mathrm{PGA})$ and time of $\mathrm{Vmax}$ \\
\hline \multirow{8}{*}{ 总 } & RT-LT (s) & interval between lever contact and onset of lever motion (reaction time) \\
\hline & F-100 (N) & force compressing the lever $100 \mathrm{~ms}$ after lever contact \\
\hline & TQ-100 (N/mm) & $3 \mathrm{D}$ lever torque $100 \mathrm{~ms}$ after lever contact \\
\hline & $\operatorname{Fmax}(\mathrm{N})$ & maximal force compressing the lever \\
\hline & $\mathrm{TQmax}(\mathrm{N} / \mathrm{mm})$ & maximal 3D lever torque \\
\hline & $\mathrm{t}(\mathrm{Fmax})(\mathrm{s})$ & interval between lever contact and Fmax \\
\hline & $\mathrm{t}(\mathrm{TQmax})(\mathrm{s})$ & interval between lever contact and TQmax \\
\hline & $\mathrm{LT}(\mathrm{s})$ & interval between onset and end of lever motion (lever time) \\
\hline
\end{tabular}

"Movement onset and end were defined as the time when movement velocity first exceeded or dropped below $5 \%$ of peak momentary velocity, respectively. Aperture peak was defined as peak momentary aperture. Fixation onset and end were defined as an interval of $\geq 100 \mathrm{~ms}$ ( 5 samples) between saccades (Steinberg \& Bock, 2013b).

group promotion with subjects in group prevention by analyses of Co-Variance (ANCoVAs), using the between-factor Priming and the covariate IRS.

\section{Results}

The questionnaire yielded an IRS score of 1.14 \pm 1.25 across all subjects, with no strong difference between the promotion and prevention group $(\mathrm{t}(46)=$ $-0.05 ; \mathrm{p}>0.05)$.

Table 2 shows the ANOVA results for parameters denoting means in the second column and for those denoting CVs in the third. Collectively, 31 parameters showed significant effects of Context, which are too many for a meaningful factor analysis, given the limited number of subjects. We therefore decided to constrain factor analysis to the 22 parameters with highly significant $(p<0.001)$ effects of Context. The outcome, presented in Table 3 , is quite similar to our earlier work (Bock \& Züll, 2013; Steinberg \& Bock, 2013b): we yielded five orthogonal factors, with GF1 representing movement speed, GF2 grip forces, GF3 the skewness of hand and finger profiles, GF4 hand transport and GF5 the synchronization of transport and grasping; taken together, those factors explain $73,7 \%$ of total variance. ANCoVAs of the factor values yielded significant effects of Priming on GF1 $(F(1,45)$ $=24.39 ; \mathrm{p}<0.001), \operatorname{GF} 4(\mathrm{~F}(1,45)=7.19 ; \mathrm{p}<0.01)$ and GF5 $(\mathrm{F}(1,45)=4.07 ; \mathrm{p}<0.05)$ while the covariate was not significant (all $\mathrm{p}>0.05$ ).

A factor analysis of the seven parameters with significant effects of Priming (see Table 2) yielded one single factor explaining $72.8 \%$ of total variance. All parameters loading strongly $(>0.6)$ on that factor represented timing and its variability (TT, CV TT, GT, t(PGA), sync-peak, Rt LT, t(Fmax)). ANCoVA of factor values showed a significant effect of Priming $(\mathrm{F}(1,45)=36.04 ; \mathrm{p}<0.001)$, while the covariate was not significant $(\mathrm{p}>0.05)$.

A factor analysis of the fourteen parameters with significant effects of Priming x Context (see Table 2) yielded four orthogonal factors explaining $81.9 \%$ of variance. According to Table 4, factor F1 represents time-related parameters, factor F2 represents the synchronization of transport and grasping, factor F3 the aperture profile and factor F4 represents the hand inclination. ANCoVAs with factor scores showed significant Priming effects on GF1 $(\mathrm{F}(1,45)=10.53$; $\mathrm{p}$ $<0.01)$, GF2 $(\mathrm{F}(1,45)=6.23 ; \mathrm{p}<0.05)$, GF3 $(\mathrm{F}(1,45)$ $=11.19 ; \mathrm{p}<0.01)$ and GF4 $(\mathrm{F}(1,45)=5.13 ; \mathrm{p}<0.05)$, while the covariate was not significant (all $\mathrm{p}>0.05$ ). 
Table 2: Outcome of ANOVAs for all parameters*

\begin{tabular}{|c|c|c|c|c|c|c|c|}
\hline & \multirow[b]{2}{*}{ parameter } & \multicolumn{3}{|c|}{ ANOVAs of means } & \multicolumn{3}{|c|}{ ANOVAs of CVs } \\
\hline & & Context & Priming & Context ${ }^{*}$ Priming & Context & Priming & Context ${ }^{\star}$ Priming \\
\hline \multirow{5}{*}{ 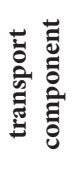 } & $\mathrm{TT}(\mathrm{s})$ & $71.00^{\star * *}$ & $5.06^{*}$ & $4.95^{\star}$ & 2.75 n.s. & $6.50^{*}$ & $8.46^{\star *}$ \\
\hline & $\operatorname{Vmax}(\mathrm{cm} / \mathrm{s})$ & $48.53^{\star * *}$ & 2.77n.s. & 3.36n.s. & $1.40 \mathrm{n} . \mathrm{s}$. & 0.70n.s. & $5.62^{\star}$ \\
\hline & Skew-T (s) & $21.32^{\star * *}$ & 0.01n.s. & 1.54 n.s. & $16.43^{\star * *}$ & 0.02 n.s. & 1.00n.s. \\
\hline & Detour-V $(\mathrm{cm})$ & $41.61^{\star * *}$ & $0.28 \mathrm{n} . \mathrm{s}$ & 0.00 n.s. & 2.37 n.s. & 0.49n.s. & 1.47n.s. \\
\hline & Detour-H $(\mathrm{cm})$ & $27.57^{\star * *}$ & 0.88n.s. & 0.02 n.s. & $14.69^{* * *}$ & $2.12 \mathrm{n} . \mathrm{s}$ & 2.15n.s. \\
\hline \multirow{10}{*}{ 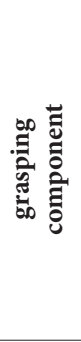 } & GT (s) & $102.74^{* * *}$ & $8.48^{\star *}$ & $7.81^{\star *}$ & $5.35^{\star}$ & 0.64n.s. & $5.43^{\star}$ \\
\hline & PGA $(\mathrm{cm})$ & $2.77 \mathrm{n} . \mathrm{s}$. & 2.39n.s. & 0.48 n.s. & 1.89n.s. & 0.41n.s. & 1.46n.s. \\
\hline & $\mathrm{t}(\mathrm{PGA})(\mathrm{s})$ & $133.50^{* * *}$ & $7.97^{\star *}$ & $6.07^{\star}$ & $5.42^{\star}$ & 0.88n.s. & 0.60n.s. \\
\hline & Peaks & $15.55^{* * *}$ & $1.27 \mathrm{n} . \mathrm{s}$. & $4.43^{*}$ & 0.56 n.s. & 0.15 n.s. & $7.41^{\star *}$ \\
\hline & $\mathrm{t}(\mathrm{FGA})(\mathrm{s})$ & $5.45^{\star}$ & 3.03n.s. & $4.83^{*}$ & $1.36 \mathrm{n} . \mathrm{s}$. & 3.08n.s. & 0.62 n.s. \\
\hline & skew-G & $91.04^{* * *}$ & 0.40n.s. & 0.21 n.s. & $7.20^{*}$ & 0.18 n.s. & $0.27 \mathrm{n} . \mathrm{s}$. \\
\hline & Incli-start $\left(^{\circ}\right)$ & 0.19 n.s. & 0.31 n.s. & 0.99n.s. & 0.10n.s. & $1.12 \mathrm{n} . \mathrm{s}$. & 0.88 n.s. \\
\hline & Incli-100 $\left(^{\circ}\right)$ & 1.56 n.s. & 0.81 n.s. & 3.20 n.s. & $1.41 \mathrm{n} . \mathrm{s}$. & $1.01 \mathrm{n} . \mathrm{s}$. & 0.19 n.s. \\
\hline & Incli-PGA $\left(^{\circ}\right)$ & 3.87n.s. & 0.26 n.s. & $4.30^{\star}$ & 0.76n.s. & 0.21 n.s. & 0.66n.s. \\
\hline & Incli-end $\left(^{\circ}\right)$ & $2.82 \mathrm{n} . \mathrm{s}$. & 0.01n.s. & 0.74n.s. & & & \\
\hline \multirow{2}{*}{ 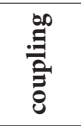 } & Sync-start (s) & $41.29^{* * *}$ & 3.94n.s. & 1.69n.s. & 0.05n.s. & 0.01n.s. & 0.64n.s. \\
\hline & Sync-peak (s) & $71.24^{\star * *}$ & $4.63^{\star}$ & 3.68n.s. & 0.40n.s. & 2.05n.s. & 0.28 n.s. \\
\hline \multirow{8}{*}{ 光 } & Rt-LT (s) & $15.43^{* * *}$ & $4.28^{\star}$ & $5.62^{\star}$ & $6.50^{\star}$ & 0.24 n.s. & 0.58n.s. \\
\hline & $\mathrm{F}-100(\mathrm{~N})$ & $32.04^{* * *}$ & 1.11n.s. & 0.05 n.s. & 2.81n.s. & $1.45 \mathrm{n} . \mathrm{s}$. & $4.14^{\star}$ \\
\hline & TQ-100 (N/mm) & $27.72^{* * *}$ & 2.24n.s. & 0.13n.s. & $0.18 \mathrm{n} . \mathrm{s}$ & 1.54n.s. & 3.96n.s. \\
\hline & $\operatorname{Fmax}(\mathrm{N})$ & $31.21^{\star \star *}$ & 0.48 n.s. & 0.81 n.s. & $20.06^{* * *}$ & 0.96n.s. & $1.25 \mathrm{n} . \mathrm{s}$. \\
\hline & TQmax $(\mathrm{N} / \mathrm{mm})$ & $38.69^{\star * *}$ & 0.28n.s. & 0.90n.s. & $7.68^{\star *}$ & 0.22 n.s. & 0.09n.s. \\
\hline & $\mathrm{t}($ Fmax $)(\mathrm{s})$ & $102.71^{\star * *}$ & $8.48^{\star *}$ & $7.81^{\star *}$ & $7.96^{\star *}$ & 0.10n.s. & 1.98n.s. \\
\hline & t(TQmax) (s) & $15.63^{\star * \star}$ & 3.40n.s. & $4.68^{\star}$ & $6.74^{\star}$ & $0.18 \mathrm{n} . \mathrm{s}$. & 0.67 n.s. \\
\hline & $\mathrm{LT}(\mathrm{s})$ & $13.24^{\star * \star}$ & 1.69n.s. & 0.26n.s. & $9.86^{\star *}$ & $3.88 \mathrm{n} . \mathrm{s}$ & 2.62n.s. \\
\hline
\end{tabular}

"The left part shows the F-values (degreees of freedom $=44$ ) for every ANOVA of single means of parameters and the right part shows the corresponding ANOVAs on CVs. n.s., $* * *$ and $* * * \mathrm{p}>0.05, \mathrm{p}<0.05, \mathrm{p}<0.01$ and $\mathrm{p}<0.001$ respectively.

Table 3: Outcome of factor analysis for Context effects*

\begin{tabular}{|c|c|c|c|c|c|c|}
\hline & acronym & GF1 & GF2 & GF3 & GF4 & GF5 \\
\hline \multirow{7}{*}{ 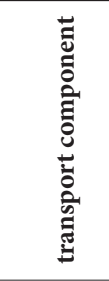 } & $\mathrm{TT}$ & 0.91 & & & & \\
\hline & Vmax & & & & & \\
\hline & Skew-T & & & 0.72 & & \\
\hline & CV skew-T & & & & & \\
\hline & Detour-H & & & & 0.76 & \\
\hline & CV detour-H & & & & -0.85 & \\
\hline & Detour-V & & & & & \\
\hline \multirow{4}{*}{ 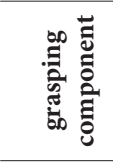 } & GT & 0.86 & & & & \\
\hline & Peaks & & & & 0.61 & \\
\hline & $\mathrm{t}(\mathrm{PGA})$ & 0.78 & & & & \\
\hline & Skew-G & & & 0.63 & & \\
\hline \multirow{2}{*}{ 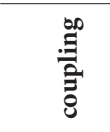 } & Sync-start & & & & & 0.87 \\
\hline & Sync-peak & & & & & 0.88 \\
\hline \multirow{9}{*}{ 总 } & Rt-LT & 0.94 & & & & \\
\hline & LT & & 0.60 & & & \\
\hline & F-100 & & -0.88 & & & \\
\hline & Fmax & & -0.75 & & & \\
\hline & CV Fmax & & & & & \\
\hline & TQ-100 & & -0.82 & & & \\
\hline & TQmax & & -0.77 & & & \\
\hline & $\mathrm{t}(\mathrm{Fmax})$ & 0.90 & & & & \\
\hline & $\mathrm{t}(\mathrm{TQmax})$ & 0.94 & & & & \\
\hline $\begin{array}{l}\% \text { total } \\
\text { variance }\end{array}$ & & 0.26 & 0.16 & 0.09 & 0.09 & 0.11 \\
\hline
\end{tabular}

*Scores are factor loadings, only values $\geq 0.6$ are shown. All parameters with highly significant $(\mathrm{p}<0.01)$ ANOVA effects of Context were selected for this analysis. The bottom row indicates the fraction of total variance explained by the respective factor. GF stands for grasping factor. 
To illustrate the Priming x Context dependence of each factor according to table 4, Fig. 2 shows the mean values across all parameters with loadings of more than 0.6 on the respective factor. Fig. 2 illustrates that motivational focus had a stronger effect on $\mathrm{E}$ than on $\mathrm{L}$ for two factors (F1 and F2), a stronger effect on $L$ than on $E$ for a third factor (F3), and a differential effect on $L$ and $E$ for the fourth factor (F4). ANOVA effects for Fig. 2 are shown in table 5.

Table 4: Outcome of factor analysis for Context x Priming effects*

\begin{tabular}{|c|c|c|c|c|c|}
\hline & acronym & F1 & F2 & F3 & F4 \\
\hline \multirow{2}{*}{ 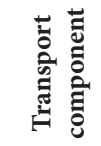 } & TT & 0.86 & & & \\
\hline & CV Vmax & 0.74 & & & \\
\hline \multirow{5}{*}{ 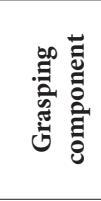 } & GT & 0.77 & & & \multirow{5}{*}{0.89} \\
\hline & CV GT & & 0.79 & & \\
\hline & $\mathrm{t}(\mathrm{PGA})$ & 0.64 & & & \\
\hline & Incli-PGA & & & & \\
\hline & Peaks & & & -0.86 & \\
\hline ن & Sync-peak & & 0.88 & & \\
\hline \multirow{6}{*}{ 总 } & $\mathrm{t}(\mathrm{FGA})$ & 0.84 & & & \\
\hline & $\mathrm{CV} t$ (FGA) & & & & \\
\hline & Rt LT & 0.90 & & & \\
\hline & $\mathrm{t}($ Fmax $)$ & 0.87 & & & \\
\hline & $\mathrm{t}(\mathrm{TQmax})$ & 0.90 & & & \\
\hline & CV F-100 & & & & \\
\hline $\begin{array}{c}\% \text { total } \\
\text { variance }\end{array}$ & & 0.42 & 0.17 & 0.11 & 0.10 \\
\hline
\end{tabular}

*Scores are factor loadings, only values $\geq 0.6$ are shown. All parameters with significant $(\mathrm{p}<0.05)$ ANOVA effects of Context*Priming were selected for this analysis. The bottom row indicates the fraction of total variance explained by the respective factor. GF stands for grasping factor.
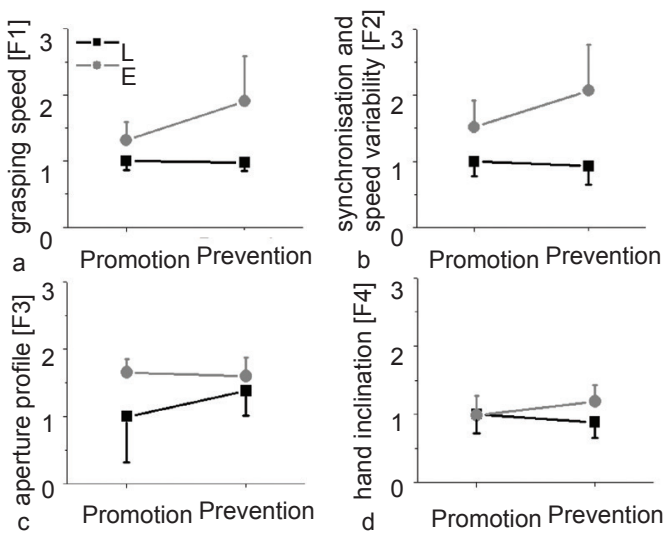

Figure 2: Across-parameter means for the Priming x Context factors presented in Table 4. To construct each plot, we selected all parameters loading high $(>0.6)$ on the respective factor, normalized each parameter by division with the parameter mean for the promotion focus in L, and then averaged across all normalized parameters. The displayed value for the promotion focus in $\mathrm{L}$ is therefore 1.00 in a-d. F and p-values of ANOVA results are shown in table 5. Error bars represent between-subject standard deviations.
Table 5: Outcome of ANOVAs on global parameter scores*

\begin{tabular}{llll}
\hline Grasping factor & \multicolumn{3}{l}{ ANOVA effects } \\
\hline & Context & Priming & Context ${ }^{\star}$ Priming \\
F1 & $30.86^{* *}$ & $6.54^{*}$ & $7.54^{* *}$ \\
F2 & $42.6^{* * *}$ & 3.57 n.s. & $6.03^{\star}$ \\
F3 & $13.04^{* * *}$ & 1.80 n.s. & 3.30 n.s. \\
F4 & 3.64 n.s. & 0.30n.s. & $4.43^{*}$ \\
\hline
\end{tabular}

"F-values (degreees of freedom $=44$ ) for every ANOVA on global factor scores. n.s., ${ }^{*}, * *$ and ${ }^{* * *} \mathrm{p}>0.05, \mathrm{p}<0.05, \mathrm{p}<0.01$ and $\mathrm{p}<0.001$ respectively. GF stands for grasping factor.

\section{Discussion}

Our study evaluated the hypothesis that the contextdependence of grasping is related to a higher motivationsensitivity in L than in E; this should be reflected by significant and consistent Priming $x$ Context interactions for a majority of response parameters. To investigate we manipulated subjects' motivation focus once through a standard priming task administered before the actual experiment, and once through linking the experiment to potential gains or losses.

Our data confirms once more that grasping differs between $\mathrm{E}$ and $\mathrm{L}$, and that these differences can be traced back to multiple independent causes (Bock \& Hagemann, 2010; Bock \& Steinberg, 2012; Bock \& Züll, 2013; Steinberg \& Bock, 2013a; Steinberg $\&$ Bock, 2013b). The data also documents a main effect of Priming on several time-related parameters; this suggests according to the additive factor method (Sternberg, 1969) $)^{1}$ that some stages of the sensorimotor system are sensitive to motivation irrespective of context. Further and most importantly for the purposes of our study, we observed significant Context x Priming interactions on 14 parameters, which could be reduced to four orthogonal factors. This suggests - in analogy to the additive factor method - that four sensorimotor stages are sensitive to both motivation and context.

The emergence of significant Priming $\mathrm{x}$ Context interactions is in agreement with the above mentioned hypothesis. However, this hypothesis specifically predicts that those interactions consistently reflect a higher priming-sensitivity in L than in E, which was only the case for one of four factors. Further, that factor mainly represents one single grasping parameter, i.e., only one of 49 parameters supports the hypothesis. We therefore failed to obtain strong evidence for that hypothesis, and conclude that context-dependence may be related to factors other than motivation. We plan to explore those factors in future work. One of the possible candidates is release of movements by external triggering in $\mathrm{L}$, versus by volition in $\mathrm{E}$ : the release mode is known to affect both the behavioural characteristics and the neural substrate of movements (Deubel, 1995; Mort et al., 2003; Waszak et al., 2005).

1 This method maintains that two factors having only main effects on a process impinge upon different stages of that process, while two factors having an interactive effect impinge upon the same stage. 
Our data doesn't support a generally stronger effect of motivation in L than in E, as hypothesized, but it does support a differential effect: motivation had a stronger effect in L for one factor, and a stronger effect in $\mathrm{E}$ for three factors. Referring again back to the additive factors method, this pattern suggests that one of the sensorimotor stages involved in L and three of the sensorimotor stages involved in E are motivation-sensitive. The general fact that stages are sensitive to motivational manipulation is not unexpected: it has been reported in a number of earlier studies that sensorimotor performance depends on motivation (Kleinsorge, 2001; Pessiglione et al., 2007; Schmidt, Kleinbeck, \& Brockmann, 1984).

It would be desirable in future work to exploit the fact that people differ with respect to their habitual regulatory focus: some are chronically more prevention-orientated, while others are chronically more promotion-orientated (Higgins, 2000; Shah, Higgins, \& Friedman, 1998). When habitual and experimentally induced focus are compatible - i.e., when a "regulatory fit" is established - subjects' performance benefits both on cognitive (e.g. Keller \& Bless, 2006) and on sport tasks (e.g. Plessner et al. 2009). Based on this, one could evaluate in future work the effects of regulatory fit in L versus in $\mathrm{E}$.

\section{Acknowledgement}

We thank Sarah Scherhag and Judith Horch for their help in data acquisition, and Thomas Kesnerus for technical support. This research was supported by a Grant from the German Ministry for Economy and Technology, administered through the German Space Agency DLR (50WB0825).

\section{Conflict of interest}

The authors declare that they have no conflict of interest.

\section{References}

Bock, O., \& Hagemann, A. (2010). An experimental paradigm to compare motor performance under laboratory and under everydaylike conditions. Journal of Neuroscience Methods, 193, 24-28.

Bock, O., \& Steinberg, F. (2012). Age-related deficits of manual grasping in a laboratory versus in an everyday-like setting. Ageing Research, 3, 48-52.

Bock, O., \& Züll, A. (2013). Characteristics of grasping movements in a laboratory and in an everyday-like context. Human Movement Science, 32, 249-256.

Brockner, J., Higgins, E. T., \& Low, M. B. (2004). Regulatory focus theory and the entrepreneurial process. Journal of Business Venturing, 19, 203-220.

Deubel, H. (1995). Separate adaptive mechanisms for the control of reactive and volitional saccadic eye movements. Vision Research, $35,3529-3540$

Fabrigar, L. R., Wegener, D. T., MacCallum, R. C., \& Strahan, E. J. (1999). Evaluating the use of exploratory factor analysis in psychological research. Psychological Methods, 4, 272-299.

Friedman, R. S., \& Förster, J. (2005). The influence of approach and avoidance cues on attentional flexibility. Motivation and Emotion, $29,69-81$.

Friedman, R.S., \& Förster, J. (2001). The effects of promotion and prevention cues on creativity. Journal of Personality and Social Psychology, 81, 1001-1013.

Glickstein, M. (2000). How are visual areas of the brain connected to motor areas for the sensory guidance of movement? Trends in Neurosciences, 23, 613-617.
Goodale, M. A. (2011). Transforming vision into action. Vision Research, 51, 1567-1587.

Grafton, S. (2010). The cognitive neuroscience of prehension: recent developments. Experimental Brain Research, 204, 475-491.

Henry, F. M., \& Rogers, D. E. (1960). Increased response latency for complicated movements and a "memory drum" theory of neuromotor reaction. Research Quarterly of the American Association for Health, Physical Education, \& Recreation, 31, 448-458.

Higgins, E. T. (1997). Beyond pleasure and pain. American Psychologist, 52, 1280-1300.

Higgins, E. T. (1998). Promotion and prevention: Regulatory focus as a motivational principle. Advances in Experimental Social Psychology, 46, 1-46.

Higgins, E. T. (2000). Making a good decision: Value from fit. American Psychologist, 55, 1217-1230.

Horn, J. (1965). A rationale and test for the number of factors in factor analysis. In Psychometrika (Vol. 30, pp. 179-185): Springer New York.

Keller, J., \& Bless, H. (2006). Regulatory fit and cognitive performance: the interactive effect of chronic and situationally induced self-regulatory mechanisms on test performance. European Journal of Social Psychology, 36, 393-405.

Kleinsorge, T. (2001). The time course of effort mobilization and strategic adjustments of response criteria. Psychol Res, 65, 216-223.

Knierim, J. J., \& Van Essen, D. C. (1992). Visual cortex: cartography, connectivity, and concurrent processing. Current Opinion in Neurobiology, 2, 150-155.

Lockwood, P., Jordan, C. H., \& Kunda, Z. (2002). Motivation by positive or negative role models: regulatory focus determines who will best inspire us. Journal of Personality and Social Psychology, 83, 854.

Memmert, D., Unkelbach, C., \& Ganns, S. (2010). The impact of regulatory fit on performance in an inattentional blindness paradigm. The Journal of General Psychology, 137, 129-139.

Milner, A. D., \& Goodale, M. A. (1995). The visual brain in action. New York: Oxford University Press.

Morel, A., \& Bullier, J. (1990). Anatomical segregation of two cortical visual pathways in the macaque monkey. Archives of Neurology, 4, 555-578.

Mort, D., Perry, R., Mannan, S., Hodgson, T., Anderson, E., Quest, R., et al. (2003). Differential cortical activation during voluntary and reflexive saccades in man. Neuroimage, 18, 231-246.

Pessiglione, M., Schmidt, L., Draganski, B., Kalisch, R., Lau, H., Dolan, R. J., et al. (2007). How the brain translates money into force: a neuroimaging study of subliminal motivation. Science, 316, 904-906.

Plessner, H., Unkelbach, C., Memmert, D., Baltes, A., \& Kolb, A. (2009). Regulatory fit as a determinant of sport performance: How to succeed in a soccer penalty-shooting. Psychology of Sport and Exercise, 10, 108-115.

Rosenbaum, D. A., Chapman, K. M., Weigelt, M., Weiss, D. J., \& van der Wel, R. (2012). Cognition, action, and object manipulation. Psychological Bulletin, 138, 924-946.

Schmidt, K.-H., Kleinbeck, U., \& Brockmann, W. (1984). Motivational control of motor performance by goal setting in a dual-task situation. Psychological Research, 46, 129-141.

Shah, J., Higgins, T., \& Friedman, R.S. (1998). Performance incentives and means: How regulatory focus influences goal attainment. Journal of Personality and Social Psychology, 74, 285-293.

Steinberg, F., \& Bock, O. (2013a). Context dependence of manual grasping movements in near weightlessness. Aviation, Space, and Environmental Medicine, 84, 467-472.

Steinberg, F., \& Bock, O. (2013b). Influence of cognitive function and behavioral context on grasping kinematics. Experimental Brain Research, 225, 387-397.

Steinberg, F., \& Bock, O. (2013c). The context-dependence of grasping movements: An evaluation of possible reasons. Experimental Brain Research, 229, 587-594.

Sternberg, S. (1969). The discovery of processing stages: Extensions of Donders' method. Acta Psychologica, 30, 276-315.

Waszak, F., Wascher, E., Keller, P., Koch, I., Aschersleben, G., Rosenbaum, D., et al. (2005). Intention-based and stimulus-based mechanisms in action selection. Experimental Brain Research, 162, 346-356. 